\title{
Comment le goût esthétique vient aux enfants
}

\section{Christine Mirgalet}

\section{(2) OpenEdition}

\section{Journals}

\section{Édition électronique}

URL : http://journals.openedition.org/trema/1945

DOI : 10.4000/trema. 1945

ISSN : 2107-0997

\section{Éditeur}

Faculté d'Éducation de l'université de Montpellier

\section{Édition imprimée}

Date de publication : 1 avril 1997

Pagination : 69-76

ISSN : 1167-315X

\section{Référence électronique}

Christine Mirgalet, « Comment le goût esthétique vient aux enfants », Tréma [En ligne], 11 | 1997, mis en ligne le 01 avril 1997, consulté le 19 avril 2019. URL : http://journals.openedition.org/trema/1945 ; DOI : 10.4000/trema.1945

Ce document a été généré automatiquement le 19 avril 2019

Trema 


\title{
Comment le goût esthétique vient aux enfants
}

\author{
Christine Mirgalet
}

1 Il n'existe pas de concept d'esthétique sans concept de culture, au sens d'une appartenance à un commun système culturel, en référence à un stock de mémoire accumulée. Immédiatement apparaissent plusieurs pistes. Concernant l'enfant : qu'est-ce qui se produit au cours de son développement? (registre de la psychologie). Dans quel contexte familial ? (contexte affectif, social). Mais encore : dans quelle époque, dans quel pays, dans quel milieu social, religieux, professionnel?

Donc, schématiquement, on peut dégager un double propos: d'ordre psychologique et d'ordre sociologique.

\section{Approche d'ordre psychologique}

2 Dans ce qui relève de la psychologie, voici ce que l'on peut noter : très tôt (vers 3 ans) les petits enfants réagissent en «c'est beau / ce n'est pas beau » à propos de toutes sortes d'objets susceptibles de relever du jugement de goût. Ce qualificatif de beau contient d'abord l'idée d'acceptation ou de rejet et englobe toutes sortes d'ingrédients de natures différentes. Par ex : la famille dit «c'est laid » pour qualifier un acte à ne pas faire (c'est laid de faire un caprice, de mentir, de manger salement, etc.). Il y a donc dans les termes beau/laid une dimension morale (est beau ce qui est vrai et bien, comme chez Platon). Dans la petite enfance, on ne dissocie pas les différentes composantes de l'émotion, de même que l'on ne dissocie pas les modes de perception. Ainsi, l'enfant pourra trouver tel vêtement beau parce qu'il est doux ou qu'il sent bon. C'est beau = j'aime. Dans les premiers temps, l'enfant accepte ou rejette en bloc. Il réagit ou ne réagit pas, en fonction des résonances que déclenche en lui l'objet. Il peut aussi être indifférent: l'objet ne suscite en lui aucune réaction.

D'autre part, l'enfant associe à des valeurs émotionnelles toutes sortes d'éléments du registre formel : fréquemment, il jugera une couleur belle ou laide en fonction de la 
valeur symbolique qu'il lui attribue. Les petites filles trouveront beau le rose, qui renvoie à un univers de poupées, de robes de mariées, d'extrême féminité (danseuses de ballets classiques). Donc, pour une fillette de 4 ans, tout ce qui est rose est beau, même en dehors des références habituelles. Par opposition les petits garçons du même âge risquent de rejeter le rose, justement parce que c'est une « couleur de fille ». Nous verrons plus loin à quel point les choix esthétiques procèdent fortement du désir de s'affirmer comme appartenant à un groupe, y compris chez les adultes (ce qui montre au passage à quel point il est artificiel de séparer le registre de la psychologie de celui de la sociologie). D'autres composantes interviennent pour constituer le jugement: par exemple, les matières, les textures. Ce qui est rugueux au toucher, comporte des griffes ou des piquants, est ressenti comme agressif, donc laid. Très rapidement intervient la demande d'explication de l'adulte. Ce peuvent être les parents («mais pourquoi ne veux-tu pas mettre ta robe, pourquoi dis-tu qu'elle est laide? »)

4 A l'école, dès les petites classes maternelles, l'enseignant sollicite l'enfant pour qu'il argumente ses jugements. Celui-ci peu à peu va donc se mettre à donner des motifs pour expliquer ses choix. Ce faisant, il apprend tout à la fois à en repérer les différentes composantes ( «la sorcière est laide parce qu'elle a un nez crochu, une robe toute noire et toute déchirée, parce qu'elle est méchante, etc.»), et à nommer ses impressions. L'enrichissement $d u$ vocabulaire, comme toujours en pareil cas, alimente et enrichit simultanément la capacité de perception et de discernement. Reste que le langage n'est pas le seul témoin dans cette affaire. Ainsi, l'émotion esthétique peut exister dans le silence absolu. Il n'est pas rare de voir un enfant rester un long moment en vraie contemplation devant une image ou un objet. D'autre part, il y a ce qu'il choisit de regarder, et sur quoi on lui demande de s'exprimer (proposition d'un adulte). Il peut s'agir d'objets qui le laissent froid, ou au contraire le font vivement réagir. Ainsi, devant un dessin qu'il vient de réaliser il peut s'émerveiller, à la fois heureux et étonné du résultat. Devant celui d'un petit camarade qu'il déteste, il aura forcément un rejet (cela ne peut pas être beau, puisque c'est fait par untel). Si c'est la maîtresse qui l'a fait, c'est «forcément » beau.

Mais d'autres facteurs interviennent également: qui le montre ? À quel moment? (Si l'enfant vient d'avoir un chagrin, son jugement en est affecté, mais il n'en a pas nécessairement conscience). Progressivement, l'enfant va affiner, enrichir sa capacité à regarder et sa manière d'exprimer son jugement esthétique. Il se met à choisir de manière délibérée ses références. Par exemple, vers l'âge de 7 ans la petite fille rejettera le rose, parce qu'elle souhaite désormais se démarquer de la tranche d'âge inférieure. Il convient de repérer la part du jugement qui renvoie à un désir d'appartenance sociale, et celle qui est proprement intime. Il arrive souvent que l'enfant lui-même soit conscient de ces deux niveaux : il sait jusqu'à quel point il dit aimer ceci plutôt que cela, ce qui lui permet d'être comme ses petits camarades. Il peut aimer certaines choses en privé, et se garder de le dire aux copains par peur du ridicule. En grandissant, il va aussi apprendre que l'on peut dissocier ce que l'on juge beau de ce que l'on aime, et s'ouvrir ainsi à de nouveaux registres du goût esthétique. Vers l'âge de 10 ans il sera capable de l'exprimer ( « je trouve que c'est beau, mais cela me fait un peu peur » ou : « c'est beau, mais ce n'est pas pour moi »). Toujours de façon progressive, le petit enfant est devenu capable de dissocier ce qui procède de la vue, du goût, du toucher, de l'ouïe et de l'odorat. Il va donc peu à peu trouver que tel objet est beau même s'il sent mauvais ou qu'il pique. Autrement 
dit, il va être capable de repérer des qualités esthétiques en dehors de l'ordre émotionnel ou grégaire.

\section{Approche d'ordre sociologique : le contexte familial, l'école}

6 L'autre volet de ce qui alimente l'évolution du goût esthétique de l'enfant renvoie au collectif, relève de l'histoire et de la sociologie. L'enfant est, par définition, un adulte en devenir, un adulte qui se sera construit au sein d'un groupe social. Il va donc acquérir tout un tas de repères d'ordre esthétique à l'intérieur d'une culture donnée, en une époque donnée, mais aussi dans un groupe social particulier.

7 Ce qui relève de l'histoire correspond en gros à la connaissance d'un certain nombre de références culturelles communes : j'appartiens à une société de tradition catholique, je suis donc entouré de tous les témoignages de cette culture religieuse (le calendrier, les églises, chapelles, cathédrales, oratoires et tous ces objets architecturaux témoignant d'un récent passé chrétien, les œuvres contenues dans les musées, la musique, la littérature, etc). Les enfants reçoivent une éducation scolaire qui tient compte de tout ce passé fondateur. Ainsi, on enseigne l'évolution de l'architecture religieuse depuis le Moyen-Age jusqu'à nos jours, même si l'école est laïque. On enseigne également ce qui provient de notre passé gréco-latin, les vestiges de cette époque et le renouveau d'intérêt à la Renaissance. L'enfant est donc nourri de cet apprentissage d'un patrimoine commun, dont il est à proprement parler l'héritier, même lorsqu'il ne s'y reconnait pas vraiment (disparition quasi-totale de l'éducation religieuse dans les familles). Ce faisant lui sont fournis toutes sortes de repères pour son jugement esthétique : il découvre la notion de " chef-d'œuvre », apprend qu'il a existé des " génies » artistiques, et c'est donc à l'école que se fabriqueront quelques-uns des piliers de notre patrimoine artistique : la Joconde, archétype du chef-d'œuvre pictural, Van Gogh, le génie ignoré de son vivant et consacré à titre posthume, Versailles ou Notre-Dame de Paris comme perfections architecturales. Le jugement esthétique de l'enfant va se trouver fortement guidé par l'apprentissage scolaire. Il apprend ce qu'il convient de trouver beau dans l'art.

8 A côté de ce qu'apporte l'école, il faut prendre en compte le groupe social auquel appartient l'enfant. Ceci est du ressort de l'enquête sociologique (se référer au travail de Pierre Bourdieu dans les années 70, encore d'actualité). En effet, ce qui est enseigné s'articule de diverses manières avec ce qui lui est apporté dans son environnement familial. Il va de soi que si la famille se désintéresse totalement des questions d'ordre culturel, l'enfant a bien peu de chances d'être capable de réinvestir à son propre compte les informations apportées par l'école. Il apprendra peut-être par cœur que « la Joconde est un chef-d'œuvre et Vinci un génie", sans plus d'intérêt que pour une formule grammaticale. En revanche il pourra alimenter tout un champ de réflexion, toute une approche d'ordre esthétique pour peu que le milieu familial l'y ait déjà préparé.

Plusieurs questions se posent alors : est-il bien-fondé de vouloir transmettre un héritage culturel et esthétique par l'intermédiaire de l'école? Qui, et sur quels critères, en délimitera le contenu? Qu'en est-il des enfants dont les origines familiales ne les prédisposent pas à y accéder (classes sociales très défavorisées et très pauvres au plan culturel, mais aussi enfants issus de l'immigration, très éloignés de nos repères culturels, tels que les enfants de parents musulmans ou issus du monde asiatique)? Quelle position 
les enseignants se doivent-ils d'adopter, compte-tenu qu'il s'agit là d'un choix débordant largement sur le domaine de l'idéologie, du choix politique?

\section{La question de l'héritage culturel}

10 L'on peut considérer que la transmission de l'héritage culturel répond à un idéal républicain qui se fit jour dès les débuts de la Révolution de 1789. A cette époque, il s'agissait de «rendre au Peuple » ce qui lui revenait de droit, les biens culturels de la noblesse et de l'église, afin de permettre l'éducation du goût, la délectation esthétique et la formation des peintres. Ceci se traduisit par l'édification, pendant tout le XVIII ${ }^{\mathrm{e}}$ siècle, de nombreux musées à Paris et en province. La pensée jacobine, nourrie des idées des encyclopédistes, conduisit à concevoir que tous les musées se devaient de présenter une sorte d'échantillonnage des diverses époques et écoles. Il s'agissait en effet de rendre au peuple son bien (indûment acquis par la noblesse et le clergé grâce au labeur des plus pauvres) sur tout le territoire national, et de permettre aux futurs écoliers et aux futurs artistes de se former au contact des chefs-d'œuvres.

11 Cette conception est encore très présente dans les esprits de cette fin de $\mathrm{XX}^{\mathrm{e}}$ siècle, à la fois dans le milieu scolaire et dans le milieu muséal. L'accès aux œuvres est considéré comme relevant du service public, supposé s'adresser à tous dans un esprit égalitaire et démocratique. Depuis une vingtaine d'années, de plus en plus de musées se dotent de services pédagogiques (pas seulement en direction des scolaires, d'ailleurs). De leur côté les enseignants du primaire et du secondaire utilisent volontiers ces structures, ce d'autant qu'ils y sont encouragés de manière explicite par les programmes et instructions officielles, et par de nombreux discours des ministres de l'Education Nationale aussi bien que de la Culture. Tout porte à croire que les musées trouvent, dans une large ouverture au public scolaire, une légitimation (concernant leurs budgets de fonctionnement, entre autres) et une réponse d'ordre démocratique à l'accusation d'élitisme qui leur fut longtemps faite, cependant que l'école prouve de son côté son souci d'ouverture au monde (réponse à l'accusation d'être un milieu clos). La transmission du patrimoine artistique et l'éducation du goût sont donc partie intégrante du projet éducatif national.

Reste que le consensus qui prévalait il y a peu sur la définition de notre patrimoine artistique a été fortement malmené par la succession des avant-gardes, puis par la naissance de la pensée postmoderne dans les années quatre vingt. Les critères et les hiérarchies ayant été bousculés, la juxtaposition des genres dans la présentation de l'art contemporain, qui procède de plus en plus de l'échantillonnage indifférent et de moins en moins de la confrontation (y compris conflictuelle) conduit à un réel désarroi. Comment définir ce qu'il est bon d'appréhender au titre de l'art ? Convient-il, et comment, de mettre les scolaires en relation avec l'art actuel, faut-il reconduire les catégories anciennes (culture « majuscule» / arts populaires, par exemple) ou accepter le risque de la dispersion et de l'éclatement du sens? L'Inspection Générale en Arts Plastiques encourage depuis dix ans l'ouverture à l'art contemporain. Il n'en demeure pas moins que la plupart des enseignants continuent à véhiculer l'art selon les anciens critères, à la fois parce qu'ils leur semblent encore valides, mais aussi à cause du sentiment d'incertitude dont on sait qu'il provoque généralement un repli conservateur. Divers niveaux de l'enseignement ont la charge de susciter la rencontre des élèves avec l'art et la culture. Toutes les classes sont concernées, de la maternelle jusqu'au lycée, mais également de nombreuses disciplines : si l'instituteur est par définition pluridisciplinaire, au collège ce 
sont les professeurs d'Arts Plastiques, d'Histoire, de Français, voire de langues étrangères qui aborderont la question, chacun avec son angle de vue. Au lycée on retrouve les mêmes, auxquels vient s'ajouter l'enseignement de la Philosophie dont une partie du programme est consacrée à l'Esthétique.

Il faut souligner que seul l'enseignement des arts plastiques conjugue le côtoiement des œuvres avec la pratique plastique, qui met l'enfant en situation de création, même modeste, et de découverte des matériaux plastiques. Or il semble bien que cette conjonction des approches soit la plus apte à proposer à la fois une approche sensible, émotionnelle, curieuse, savante, une prise en compte globale par le sujet. Nous serions là dans la situation d'enseignement la plus favorable. Concernant donc cette question, l'enjeu est double: d'un côté l'accès du plus grand nombre à la culture passée et contemporaine, dans un souci égalitaire mais aussi pour permettre la continuité de la création artistique nationale, et de l'autre, la fédération des citoyens autour d'une culture commune, ce qui relève plus nettement encore d'un projet patriotique.

\section{La question de l'interculturalité}

$14 \mathrm{Si}$, au début de ce siècle, on punissait les élèves lorsqu'ils parlaient leur patois, car il fallait qu'ils soient français avant d'être limousins ou bretons, on rencontre aujourd'hui la même question s'agissant des enfants de parents non français. Deux courants de pensée contradictoires s'affrontent. Les uns considèrent que des enfants de culture familiale non française doivent recevoir une information sur leur culture, voire un enseignement de leur langue d'origine, faute de quoi ils ne parviennent pas à créer de racines, se sentant «de nulle part». L'autre tendance estime que les enfants appartiennent d'abord à l'endroit où ils grandissent. Par exemple, un enfant d'origine marocaine a plus de points communs avec ses camarades français qu'avec un autre enfant de même origine élevé, lui, en Allemagne. Il convient à ce titre de lui donner toutes les chances de s'intégrer dans une perspective française, plutôt que de l'isoler dans une particularité culturelle. Après le « droit à la différence » c'est le « droit à l'indifférence ».

La réponse pourrait être dans la prise en compte du concept d'interculturalité. Pas plus que de « races pures » il n'existe, au regard de l'histoire, de « cultures pures ». Toutes les formes d'expression artistique témoignent d'échanges, d'influences, de porosités entre les cultures (l'influence de l'Islam sur l'art médiéval, le Japonisme de Van Gogh, Picasso et l'art nègre). C'est même pour une large part le ferment de leur évolution. Si l'école prenait en charge de porter un regard sur d'autres cultures que la nôtre, et d'étudier les cas d'influences réciproques, peut-être pourrait-elle jouer son rôle fédérateur autour d'une identité commune, la culture transmise comme un patrimoine, tout en proposant un point de vue qui en relativiserait le côté monolithique et ethnocentriste. L'on peut considérer d'ailleurs que bien des enfants français sont étrangers à leur propre culture " haute ». La leur, celle dont ils se revendiquent, qualifiée de culture populaire, de masse, n'est même pas évoquée à l'école. Elle croise pourtant fréquemment l'art contemporain (Pop Art, Graffitis et Tags d'artistes). On s'orienterait peut-être vers une éducation à la tolérance dans le domaine de l'esthétique, rompant ainsi avec le « bon goût » convenu, la rigidité, l'académisme.

S'il existe une éducation au jugement esthétique, elle passe par plusieurs chemins, la famille, l'école, mais ne s'y réduit nullement. La connaissance n'est rien sans la sensibilité, l'essentiel est peut-être ailleurs, dans un libre choix de l'individu. Car, en 
définitive, la relation avec l'art ne se décrète pas de l'extérieur. Elle ne peut être que le fruit d'une démarche solitaire, procédant de la passion au moins autant que de la raison.

\section{BIBLIOGRAPHIE}

ALBERTO R., Problèmes posés par l'émergence d'une culture métisse dans l'art du XX $X^{e}$ siècle. Analyse de cas et incidences sur l'éducation artistique, Thèse de doctorat, Paris, Université de Paris VIII, 1990.

BENJAMIN W., «L'œuvre d'art à l'époque de sa reproductibilité technique », in Poésie et Révolution , Paris, Les lettres nouvelles, 1971.

BERQUE J., L'immigration à l'école de la République, Paris, La Documentation Française, 1985.

BOURDIEU P., La distinction, critique sociale du jugement, Paris, Minuit, 1979.

CLAIR J., Considérations sur l'état des beaux-arts, Paris, Gallimard, 1983.

CLIFFORD J., « Les autres, au-delà des paradigmes de préservation », in Les cahiers du Musée d'Art Moderne, Paris, Centre G. Pompidou, 1989.

DIDI-HUBERMAN G., La peinture incarnée, Paris, Minuit, 1985.

LAGOUTTE D., Enseigner les Arts plastiques, Paris, Hachette, 1995.

MICHAUD Y., L'artiste et les commissaires, Nîmes, Éd. Jacqueline Chambon, 1989.

MORIN V., «La culture majuscule », in Communications, $\mathrm{N}^{\circ}$ 6, Paris, Ecole Pratique des Hautes Etudes, 1970.

LAUDE J., La peinture française et l'art nègre, Paris. Klincksieck, 1968.

SEGALEN V., Essai sur l'exotisme. Paris. Éd. Fata Morgana, 1995.

THORNTON L., Les orientalistes, peintres voyageurs, Paris, ACR Edition, 1993-94.

UNESCO, Introduction aux études interculturelles. Paris, Unesco, 1980.

UNESCO, Esquisse d'un projet pour l'élucidation et la promotion de la communication entre les cultures, Paris, Unesco, 1980.

L'art contemporain et le musée. Les Cahiers du Musée National d'Art Moderne, Hors série, Paris, Centre G. Pompidou, 1989.

\section{RÉSUMÉS}

Comment se construit la sensibilité artistique des enfants? L'évolution psychologique se conjugue avec l'influence du milieu familial, dans un contexte culturel donné. L'école prend une large part dans cette éducation du goût. Qu'en est-il de la question de la transmission d'un héritage culturel, quel en est le bien-fondé? Comment et selon quels critères définir cet héritage? Quelle attitude peut-on avoir envers des enfants étrangers à cette culture (issus de l'immigration, ou de classes sociales très modestes) ? Quel projet culturel national peut se donner l'école? 
How is artistic sensibility built in children's minds? Their psychological evolution is combined with the family background, in any given cultural context. The school plays a large part in this educating of the taste. What may be said about the transmission of a cultural heritage, in what way is it justified? How and along which criteria can this heritage be defined ? What attitude can we have towards children to whom this culture is foreign (who come from immigrant families or families of modest social origin)? Which national cultural project can the school system propose?

INDEX

Mots-clés : école, enfant, héritage culturel, sensibilité artistique

Keywords : artistic sensibility, child, cultural heritage, school

\section{AUTEUR}

\section{CHRISTINE MIRGALET}

PRAG d'arts plastiques, IUFM de l'académie de Montpellier - site de Nîmes 